\title{
Public Relations Strategy in the use of Management Information Systems to Improve the Work of Institution
}

\author{
Maha Mustafa Omer Abdalaziz
}

\begin{abstract}
The aim of the research is to shed light on public relations strategies in the use of information systems to improve the work of institutions as an information behavior that makes a distinction in adding new value in various ways to improving the work of institutions. To this is to identify the analysis and evaluation of the effects of the use of management information systems in identifying problems and difficulties and their importance for managing public relations in revealing strategies that public relations can follow in government or private institutions in making strategic decisions leading to plans and directions for dealing with the public of institutions, and developing systems programs Administrative information according to international standards for administrative work; to enhance the image of institutions in their vision and the goals of their institutional work plan leading to an integrated understanding and scientific information of the best ways and techniques to simplify the work in addition to groups of strategies Basic final. In light of this, the subject of the research deals with the strategy of public relations in the use of management information systems to improve work in institutions, and the way in which support, decision-making and directions are contributed by the Department of Public Relations in institutions, in the use of administrative information in the organization of work as a major goal highlighting the importance of the information strategy; in addition to developing The procedures followed and communication mechanisms in developing the management level of institutions, to facilitate communication with its external partners.
\end{abstract}

Keywords: Strategy - Public Relations - Use of Management information systems, improvement of work

\section{INTRODUCTION}

Enterprise managers are now trying to pay attention to management trends in order to better interact with the increasing challenges and risks in the work environment and their high costs in order to maintain the competitive advantage of their organizations within a constantly changing world. Management Trends is a set of decisions and administrative systems that define the organization's vision and mission in the long term in light of its competitive advantages and seeks to implement it through studying, monitoring and evaluating opportunities and environmental threats and their relationships with organizational strength, weakness and achieving a balance between the interests of different parties. Accordingly, the public relations strategy in

Revised Manuscript Received on June 12, 2020.

* Correspondence Author

Dr. Maha Mustafa Omer Abdalaziz*, College of Mass Communication and Public Relations / University of Fujairah / Emirate of Fujairah / United Arab Emirates/maha@uof.ac.ae

(c) The Authors. Published by Blue Eyes Intelligence Engineering and Sciences Publication (BEIESP). This is an open access article under the CC BY-NC-ND license (http://creativecommons.org/licenses/by-nc-nd/4.0/) administrative work systems is only an important decision-making process of administrative processes, which requires a type and amount of information that differs from other processes, where the problem-solving process is closely related to the decision-making process about the strategies presented and potential constraints, and that Both processes are based on a series of activities that consist of identifying problems, working to analyze them, identifying alternatives and solutions to choosing alternatives, and then the direction in which problem-solving will be taken. Therefore, it requires a type of management information systems with specific information and specific sources in order for the public relations strategy in its decision-making process to have a positive return.

From the above in management information systems, it is the basic part of public relations strategy in making its decisions and is considered one of the topics that have been and continue to receive the attention of public relations experts in how a series of administrative information systems are based on individual judgment based on experience and available information.

\section{PROBLEM}

The research problem lies in public relations strategies in the use of management information systems to improve the work of institutions, to what extent all their operations and procedures are related to achieving planned results according to plans and trends through enhancing concepts of organizational intelligence for administrative information in order to achieve satisfactory results of excellence or leadership within the framework The rapid growth of technology to enter a stage of building capabilities and basic elements in the formulation of the system to ensure outputs that achieve its goal towards building a smart enterprise. And knowing what are the practical administrative methods used by the Public Relations Department in building strategic administrative information communication to develop the work in the institutions, so how do you map their directions for information and data to organize the administrative information systems in the institutions?

\section{METHODOLOGY}

The research relies on the descriptive and analytical approach, which describes and discusses the characteristics of the research community in order to reach the facts to obtain the data and information in question during the specific time period of the study within its specific spatial limits, and then analyze and discuss that information and data and reach specific results.

Blue Eyes Intelligence Engineering \& Sciences Publication

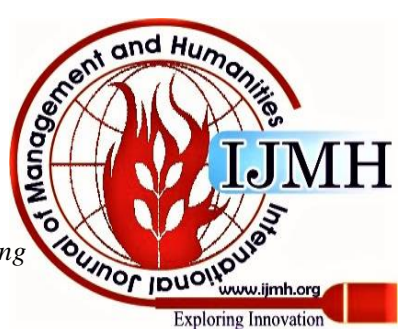




\section{LITERATURE REVIEW}

\section{The Concept of Public Relations:}

If we know that every activity in modern life depends mainly on people, and for this activity to succeed and flourish, it must know how it can deal with people, then we can estimate the multiplicity and diversity of areas that need public relations, and the importance of public relations and its effectiveness. As a science, it cares about people's opinions, directions, and attitudes towards every group or organization (1).

Public relations today are extremely important for contemporary institutions, as they aim to achieve harmony and adaptation between them and their audiences that deal with them, and with this compatibility and adaptation, contemporary institutions have a climate more favorable to their sound and stable development, while the people dealing with them have a better shared social life. (2)

Public relations as an administrative concept and a communication function developed as a result of the increasing complexity of the modern society, increased interdependence between its institutions, the increasing strength of public opinion, as well as an increase in understanding the motives and demands of individuals and groups, and gaining support, cooperation and trust by others through persuasion became part of the director's daily work in any type of Types of organizations. The administrative concept of public relations in contemporary society, which is characterized by interdependence and overlapping relations, in which all organizations have general responsibilities; hence, they must accept accountability in all their actions that affect others. And to ensure that the philosophy of each director is so that it can take into account the impact of any decision on the public (3)

The functional concept of public relations also is the need of the contemporary director to assist and advise a number of experts and consultants who provide him with advice on specialized matters that he does not have the time to do personally so that he can devote himself to administrative matters successfully. Among these, an expert or public relations consultant is chosen by senior management (4).

The primary responsibility of public relations is to create awareness of government activities at a level appropriate for the public. Which cannot be achieved now through investigation of continuous inquiry by the government to determine the feelings of the public and to provide the public with real material and explanatory information? An analysis of the specific ideological trends of the institution's personality with everything related to it and what comes from it, along with the institution's image and its importance as a basis for the social trend of public relations as a specialized profession of a special nature, can lead us to a number of conclusions that define the distinctive characteristics of this social trend and its inclusion in the service Social internally and externally at the level of social responsibility of business owners, and integration in the communication and organizational service together to serve the audience horizontally and vertically up and down and interact, to that regard taking into account the provision of communication, research and evaluation service within the framework The human dimension in contemporary management, and work to

Retrieval Number: J09490641020/2020@BEIESP accompany the public relations activities of self-criticism and the continuous self-evaluation of planning, and then consider the priorities to address the strengths and weaknesses, and push forward the strengths and the foundations of evaluation.

\section{The importance of public relations}

Public relations have become the main job that qualifies for this role and the transfer of the moral aspect of the organization, which is represented in its reputation and standing in the community in which it operates. In recent times, the demand for developing public relations departments has increased, and the reason for the demand for this branch of the administration is the role that this device plays and its importance for each institution as it transmits a picture of the activities and services it provides to the public and the public's need to obtain that information. (5)

Public relations has become extremely important in developing the trends of the idea of modern management information systems, and assigns to it a vital role related to highlighting the honorable image of the institution and the services it provides to its society and thus constitutes a communication link and communication and an active tool of interaction within the organization and outside it, the success of the institution, whether governmental or private, does not stop On what you achieve if you are unable to show this achievement to the target groups of its audience and dealers with it through offering the services provided and development programs, and this task is borne by the public relations men because of their experiences and the capabilities available to them. Lemhi Falih et al., 2014) and the reflection of the evolution of the means of communication throughout the different ages and times on the social relations between individuals and society, so these relationships evolved from simplicity to complexity until they reached their maximum in the twentieth century, and with the beginning of the third millennium. With this steady and continuous development, a certain fact is not lost on the minds, namely that human understanding and good relations that depend on cooperation and exchange of experiences between the state as well as building society and improving its economic level by creating cooperation between government agencies and departments and individuals at all levels is the essence of public relations in any society from Societies (6)

From the above, it is possible that as a result of the progress of public relations operations in societies and their importance, public relations have entered into many bodies and organizations, they can be clarified in some of these areas, namely: (7)

1. Willingness to accept the opinions and decisions of the senior leadership in the organization by the public, which is considered as a public opinion (and is one of the indicators of quality in the performance of the organization). 
2. Achieving integration, narrowing the gap between individuals and society, and working to create a state of understanding and knowledge to unify trends.

3. Clarify the tasks of government institutions and the quality of the services they provide to the public, provided that the information is transparent, credible, and presented in the appropriate form and time.

4. Carrying out awareness of the development goals of the government institution with a view to achieving public understanding and belief in them, and then cooperating with the organization's departments to achieve them.

5. Study the problems and discuss the issues of the institutions directly related to the internal and external audiences and come up with solutions that satisfy all parties.

6. Activate communication to create a state of mutual understanding between institutions and the surrounding environment in which they are within the scope of public relations.

\section{PUBLIC RELATIONS STRATEGIES IN INSTITUTIONS IN GENERAL}

The question of the importance and urgency of public relations strategies is no longer a matter of debate or debate among practitioners or contact researchers. Institutions with different orientations and outputs, whether they are service or product, have become operating in a changing and evolving environment, and the success or failure of these institutions depends on the ability to adapt to this environment and its various elements from its audiences, institutions, and groups with different directions, needs, and aspirations. This adaptation requires monitoring and studying these changes and setting up administrative programs to organize work within government sector institutions to respond to them in a way that realizes common interests between the institution and its environment. (8). Therefore, the question has become: How do you manage the public relations department in government institutions by setting strategies that organize administrative information systems in order to achieve the goals of the institution? Several studies have attributed the reasons for the lack of quality and clear strategies in government institutions and their governmental administrative programs to deal with the administrative communication program of the public relations strategy in administrative work systems is only a decision-making process of important administrative processes, which requires a type and quantity of information that differs from other processes, As the problem-solving process is closely related to the decision-making process around the strategies presented and potential constraints, and that both processes are based on a series of activities consisting of identifying problems and working to analyze them and identify alternatives and solutions. Li selection of alternatives and then the direction that will be taken to solve problems. Therefore, a type of management information system requires specific information and specific sources in order for the public relations strategy in its decision-making process to have a positive return.
Accordingly, what is meant by public relations strategies is the sum of important and independent decisions taken by an institution in order to achieve specific goals, by using multiple means of communication and techniques. And adopting an effective strategy based on a clear and achievable scientific program is the foundation of the success of the institution, which wants to pursue a transparent communication policy with its internal or external audiences, so that it may have for itself or its product and services a good image towards the masses.

From the above in management information systems is the basic part of public relations strategy in making its decisions and is considered one of the topics that have been and continue to receive the attention of public relations experts in how a series of administrative information systems are based on individual judgment based on experience and available information.

Accordingly, many researchers have indicated that the failure of many programs of administrative systems in public relations is due to a gap in managers in knowing how to switch from a planning strategy to an implementation strategy. Where you can use a specific strategy in a specific situation or use a combination of these strategies in another situation. It defines the communication strategy for MIS systems according to two main axes:

The first axis: the nature of the communication process, and the extent of public participation in this process. One end of this axis represents one-way communication, while the other end represents the two-way communication.

- The second axis: It indicates the nature of the content and meanings included in the communication messages. One of the two sides of this axis represent messages whose content and meanings express only the visions of the institution. As for the second part: it refers to the messages that express each of the institution and the public, and carry indications that reflect the visions of the two parties. Accordingly, we have four PR strategies: (9)

First: The media strategy: Communication according to these directions is one-way, and at the same time the communication content expresses the visions of the institution and carries meanings and meanings with one meaning. In these directions, information is provided to the basic masses to help them form an opinion and make decisions. Examples include press releases and Foundation publications. The strategy requires clarity of the organization's policy and goals and a mix of communication messages that express those goals. At the same time, it requires a conscious audience to search for information.

Second: The Persuasion Strategy: These trends combine the one-way communication and the communication content that expresses the visions of both the institution and the masses, and carries indications that reflect the viewpoint of the two parties. The strategy of persuasion is the basic trends in both the theories of advertising and propaganda and psychological theories. These directions are used in enterprise communications when they seek to create a direction base for the intended change.

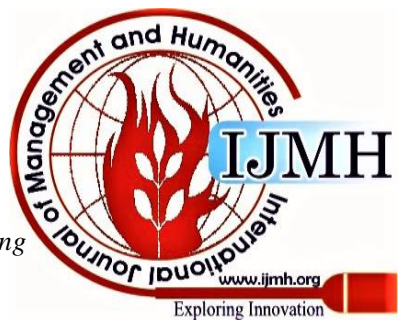


In the knowledge, attitudes, and behaviors of a particular audience. Persuasion strategy requires clear and specific goals and a mix of persuasive messages. It is usually directed to an inactive or implicit audience.

Third: Consensus-Building Strategy: These trends combine communication in two directions, and the communication content that expresses the visions of the institution. These trends are used to build strategic relationships between the organization and its external environment, or between the organization and its employees. Usually, these trends are applied when there is a conflict of interest between parties whose parties depend on their existence on the other party. For example, Institutions depend on their existence on the basic masses present in their external environment, and here is usually a conflict between the interests of the institution on the one hand, and the interests of those masses on the other hand. This requires the Foundation to achieve common ground with these audiences that achieve the minimum interests of both parties. Usually, these trends are directed to the active audience and result in the development of enterprise policies.

Fourth: The dialogue strategy: The dialogue strategy combines two-way communication, and the communication content that expresses the visions of both the institution and the masses, and carries indications that reflect the viewpoint of the two parties. These include trends in consulting the public about the institution's policies, and taking its opinion on various issues into account. The public is involved in the decision-making process. Therefore, these trends are called (facilitation strategy), where the institution works to facilitate the participation and interaction of the public in making its policies, and at the same time is keen to implement social responsibility programs. The dialogue strategy is used in related discussions Besides practicing public relations, as well as in-depth intellectual discussions about problems and crises expected to occur, and how to respond to them. These trends require communication messages from the parties to the dialogue. She usually heads to perceiving and being energetic. (10)

Fifth: The Right Time Strategy: These trends work to determine the appropriate time to broadcast or publish a statement or to announce a decision or to open a project and so on, and must take into account in determining the time and work to gain the impact of the target audience from the subject of the information or other data in order to study the circumstances surrounding the situation and the affected parties in it or affected by it.

Accordingly, it can be said that communication means and their strategies are focused on how to manage these methods and the techniques that a public relations practitioner can apply in making use of them. The means available to the PR program have become multiple between mass communication and enterprise-specific means. If this plurality and diversity in its strategies represent an advantage for administrative information systems and public relations to choose what is appropriate for its communication programs, it is equally challenging for him in how to manage these means and the relationship with those in charge of them, and in determining the appropriate means for each communication message addressed to a specific audience. Choosing the appropriate medium is linked to many worlds and limitations, including the objectives of the communication program, the nature of the target audience, and the nature of the planned communication messages. Taking into account the physical and technical characteristics of the medium.

Thus, there must be a sound organization for administrative work that is responsible for proposing and implementing systems policy in the organization, and for senior management to be convinced of the importance of (public relations management), and its role in achieving the effectiveness of management information systems in the institution.

As a result of the development of the state's role, which includes all aspects of developments in administrative information systems in all fields, and the provision of services that achieve the public interest and interest in good relations with the public, therefore it was necessary to find a specialized department in public relations whose primary goal is to build bridges of trust and communication between it and the public It is a public relations department. So we find that there is an opportunity for administrative processes developments in the development of modern management systems techniques by taking advantage of direct management information systems techniques in the conduct of all administrative, field, and training tasks and tasks for government institutions.

The amazing development in management information systems has helped to change many public relations strategies of our institutions, and the winds of this change have not and will not exclude public relations departments where the amazing development is not in public relations strategies of all institutions, whether governmental or private, where digital technology has contributed to strengthening the institution's ability to Providing information to the masses, and before that, in obtaining the information necessary to make sound decisions. These administrative information systems technologies also contributed to strengthening the institution's ability to practice public relations in influencing the content and media of issues related to issues. Foundation, and the public relations contribution to increasing the organization's ability to build good public relations with different audiences, as well as increasing the organization's ability to achieve a two-way symmetric communication from the organization to their audiences and the public to the institution. (11)

Electronic public relations also require designing more effective communication programs than traditional programs, because we live in an age of speed in which competition intensifies, as there is no place in it except for institutions that have strong bonds of trust with their audiences, this task which falls on public relations departments and with The new transformations have demonstrated electronic public relations that have proven useful in the era of the information society.

Published By:

Blue Eyes Intelligence Engineering \& Sciences Publication

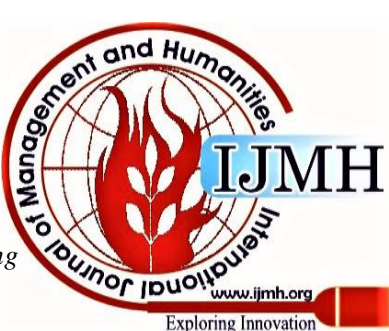




\section{THE CONCEPT OF MANAGEMENT INFORMATION SYSTEMS AND THEIR IMPORTANCE}

\section{First: The concept of management information systems}

The concept of management information systems and the overlap and some other concepts such as organizational development, generational change, and administrative reform, and the origin of this overlap may be the difference between the successor and opinions in these concepts, which is that the concept of management information systems in an attempt to develop the concept of information systems means in government institutions with no such The concept is in many aspects of other organizational concepts and it is believed that administrative systems are a translation of the term organizational development and a synonym for it by focusing on a partial view of these two concepts of interest in the management information systems device, or replacing the concept of development The term organizational and organizational management, which reflects the overall development of government institutions. (12)

Accordingly, the concept of management information systems is the administrative development and organizational development of the trend to a number of areas represented in:

a. The overlap and similarity between functions, characteristics, goals, and concepts.

b. The practical reality in our institutions indicates that the departments are in the process of change, development, and organization in all its aspects bearing the administrative name of the departments.

And the concept of management information systems means a set of secondary systems or a series of secondary systems, each of which is an integrated system with its inputs, processes and outputs. For example, it is the introduction of administrative information (inputs) and then we make it ready for implementation in the form of (outputs).

The use of administrative business information systems has increased in the last two decades by public or private organizations, and studies have shown that a number of these systems have succeeded while a number of them have failed, and this failure is not due to insufficient quality of technology or the system used, but this has occurred as a result Therefore, other specific factors were not taken into account reactions and organizational factors by system designers, and that the standards for developing management information systems may differ from one person to another, but there are general advantages that describe the framework of any successful MIS information system, which is the accuracy and validity of the system, and independence and are used in a way Hope by all beneficiaries, as the presence of these characteristics supports the system and raises its quality, and then it succeeds. The secure information system helps in raising the quality of the organization and contributes to the overall quality of management by making its responsibilities the responsibility of every individual in the organization, as the designer, manager, employee and worker are part Important because it is related to the daily activity of the institution and means the system failed not only to stop it, but not to use it in an effective way, due to problems in design, costs, data and operation .
As for success, this means that a high-quality information system meets all the goals and requirements of the beneficiary in a manner that covers all required work procedures now and in the future and works in the form of correcting the technical method without errors, and that it is easy to maintain and develop, provided that the results of the material and moral benefits of the system exceed the total costs that were spent on him. The application of MIS systems in government institutions faces a host of difficulties. (13) From the above, management information systems can be defined as "interference to make a change in the administrative organization as a result of dissatisfaction with its performance, which requires setting a strategy for moving the driving forces in the organization, which depends on the methods and means that help to accelerate the change in the administrative work systems."

Second: The importance of management information systems:

Management information systems have a great importance for the institutions that work in government sectors in general and the institutions today in particular, in terms of their urgent and urgent need to raise the level of their performance and to be in a state of prolonged exploitation on the one hand, and scientific progress in all its aspects on the other hand, and the large number of Developments and changes in the internal and external environment of institutions at all social, political and economic levels.

Where the importance of management of administrative systems lies in many reasons, including, (14)

1. Maximum benefit from the material and human resources organizations to work to achieve the goals that were designed to meet the needs of the functioning of the administrative information systems and how to organize with the capabilities of government institutions that possess technical materials and human resources.

2. The continuous increase in organizational developments, especially administrative information systems, which are reflected in the increased importance of the development of management information systems for government institutions, so that they can meet the needs and aspirations of the public.

3. Most administrative bodies in the Arab countries in particular and in the Emirates have worked for long periods of time, paying attention to a difference in environmental goals in terms of data, systems, and information of administrative information systems and the environment enjoyed by institutions and organizations with the characteristics of the current data environment, which led to a review of the methods, means, and mechanism of the organization According to the new environmental data.

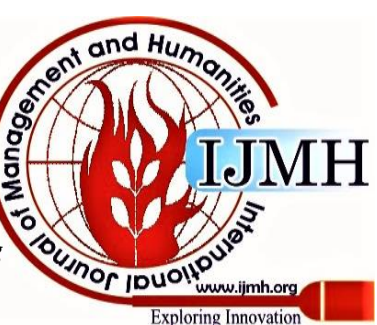


The thing that led to the necessity of developing and reviewing the components of its administrative apparatus in order to be able to achieve these new goals.

From the above it can be said that the importance of management information systems has become considered one of the most important components of the development process for individuals and institutions alike, and that the practice of management information systems with different positive ideas and methods, constitutes a positive and favorable work environment for the work of individuals and work groups, each in the field of the continuous generation new ideas Outstanding performance, or constructive solutions to the expected problems inside or outside the organization, out of the ordinary in those areas and transcending the traditional in thought and work, in an attempt to increase the internal and external efficiency of the institution and its growth and survival and increase its competitiveness." (15)

It is worth noting that the proper planning of administrative information systems for administrative development is through the compatibility of objectives with available capabilities. Working on linking administrative information systems and linking them to administrative development with the environment: The relationship between development and the surrounding environment is extremely important, and ignoring the surrounding environment may lead to a failure of the administrative development process, so the development process must relate to the surrounding environment with its habits, values, principles and culture because some methods And administrative and organizational methods and development methods of facilities in an environment that differs in many of its data from the environment surrounding the process of administrative systems. To this continuity in the process of management information systems, which is undoubtedly one of the most important characteristics of management information systems; as many management scholars have mentioned it as a planned and long-term effort, and this indicates that management information systems are not accused of solving existing problems only and working to recognize problems and obstacles Before it occurred through looking ahead. Challenges and challenges and know the opportunities and threats and work to employ them to avoid problems in the future. Adding inclusivity in management information systems: The holistic view of things in all aspects that gives more accurate results and positive work and less errors and makes judgment on things from their comprehensiveness to organizational and administrative aspects to achieve the best results.

\section{PUBLIC RELATIONS STRATEGY IN THE USE OF MANAGEMENT INFORMATION SYSTEMS TO IMPROVE THE WORK OF INSTITUTIONS}

Adopting an effective strategy based on a clear and achievable scientific program is the foundation of the success of the organization, which wants to pursue a transparent communication policy with its internal or external audiences so that itself or its product and services can have a good image towards the masses.
Therefore, we find that the institution that believes in the role of communication and public relations as a basic function for effective management allocates an interest or a special section that is usually called several labels, such as the public relations department, the communication department, and it also assigns one or more employees who are responsible for preparing and implementing public relations programs, and preparing a business strategy to implement these programs, with the aim of creating and building a good image, and trusting relationships with the masses that deal with this institution, and therefore the public relations strategy in the work of administrative systems consists of four main components:

First: Public Relations Strategy for Management Information Systems through Environmental Survey:

An environmental survey in management information systems is a set of internal or external factors or variables that occur inside or outside the boundaries of the organization and that affects the effectiveness and efficiency of organizational performance. The environmental survey aims to monitor, evaluate and analyze the information internally and externally to put it before the public relations strategies makers in the organization and its goal is to identify factors, trends or internal and external elements that determine the future of the organization, as the external environment contains variables (opportunities and threats) outside the borders of the institution.

Second: The public relations strategy for administrative information systems through the societal environment:

Whereas, the societal environment includes all external forces that influence short and long organizational decisions, including economic, technological, cultural, social, political, and legislative forces.

Accordingly, public relations strategies in administrative information systems work to predict the strength of competition and challenges facing government institutions to the role of information with regard to administrative information systems and acceleration in the development of administrative information systems and computer-based information work systems and the use of modern business and information technologies that have brought about a significant change in the field of management With its various functions, owning an administrative information system is no longer the decisive factor in the success of institutions and achieving them for competitive advantage only, but there are many aspects that should be taken into account, the most important of which are the indicators of success The information system for administrative work, given that this aspect reflects on the managerial behavior of the beneficiaries at the time, the biggest role in the success of the design and implementation of the information system.

\section{Third: The public relations strategy for administrative} information systems through the work environment: By that, we mean all the elements or groups that have a direct impact on the basic organization, and some of its components include shareholders, government, and interest groups.

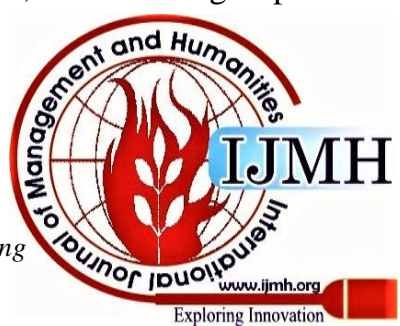


And that the simplest way to know the correct administrative work environment is to do what is known as the SWOT analysis, which is an analysis that includes the strengths and is the knowledge of the positive characteristics that help the organization to achieve the goals of administrative and strategic information systems and also to identify weaknesses, which can create obstacles that limit systems The administrative information of the institution, and this brings the role of opportunities and threats available to reach a strategic balance point between the elements, trends in the external environment, and the elements, trends in the internal environment of the institution. Public Relations Managers can obtain this information through various reports such as budgets, ratios, financial rates, profit and loss statements, and research related to employee satisfaction and behavior.

\section{DISCUSS THE RESEARCH FINDINGS}

Through this research, the researcher has addressed the descriptive and analytical analysis of the data collected from the study sample, and then the researcher analyzed these data using the statistical packages program in the social sciences. Several 100 questionnaires were distributed to several public relations workers in government and private institutions, which are their strategies in management information systems, and the following were:

Table No. (1) Distribution of sample individuals according to age

\begin{tabular}{c|c|c} 
Age & Respondents & Percentage \\
\hline UNDER 25 YEARS & 10 & 10 \\
OLD & & \\
$\mathbf{2 5}-\mathbf{3 5}$ & 30 & 30 \\
$\mathbf{3 6}-\mathbf{4 5}$ & 40 & 40 \\
OVER 45 YEARS & 20 & 20 \\
OLD & & \\
\hline TOTAL & 100 & $\mathbf{1 0 0 \%}$
\end{tabular}

The table shows the distribution of the sample population according to age, where we find that $(10 \%)$ of the total sample surveyed are less than 25 years old, (30\%) of the sample population ranged between $25-35$ years old, (40\%) of the surveyed sample ranged from Their ages are between $36-45$ years, (20\%) of the respondents were over 45 years old.

Table No. (2) Distribution of sample individuals according

\begin{tabular}{c|c|c}
\multicolumn{2}{c}{ to the Occupation } \\
Occupation & $\begin{array}{c}\text { Respondents } \\
\text { Percentage }\end{array}$ \\
\hline SUPERVISOR & 15 & 15 \\
HEAD OF THE & 25 & 25 \\
DEPARTMENT & & \\
MANAGER & 22 & 22 \\
OTHERS & 38 & 38 \\
\hline TOTAL & 100 & $\mathbf{1 0 0 \%}$
\end{tabular}

Through the above table, by distributing Al Ain personnel according to the job titles, we find that $(10 \%)$ of the respondents have a job title in a supervisor, (25\%) of the respondents have a job title in a department head, (22\%) of the respondents have a job title in a manager, while (38\%) of the respondents carry Others.
Table No. (3) Analysis of the correlation between knowledge of the concept of management information systems and public relations management in institutions Ferries Respondents Percentage

\begin{tabular}{c|c|c}
\hline STRONGLY AGREE & 40 & 40 \\
STRONGLY & 25 & 25 \\
NEUTRAL & 15 & 15 \\
NOT AGREE & 10 & 10 \\
STRONGLY & 10 & 10 \\
DISAGREE & & \\
\hline TOTAL & 100 & $\mathbf{1 0 0 \%}$
\end{tabular}

We note through the table on the distribution of sample individuals to the extent of their knowledge of the concept of management information systems in the Department of Public Relations in institutions, we find that the majority of respondents consider that the concept of management information systems in public relations is the core of the strategic work, where the percentage of those who agree strongly (40\%) of the total The respondent sample, as well as (25\%) of the sample agree on the need to follow a public relations strategy in organizing their management information systems in their institutions, while the percentage of those who disagree is $10 \%$ and strongly disagree, at $10 \%$.

Table No. (4) Analysis of the correlation between the relationship between public relations strategies and administrative information systems in making basic decisions in institutions

\begin{tabular}{c|c|c} 
Ferries & Respondents & Percentage \\
\hline STRONGLY AGREE & 20 & 20 \\
STRONGLY & 30 & 30 \\
NEUTRAL & 10 & 10 \\
NOT AGREE & 20 & 20 \\
STRONGLY DISAGREE & 20 & 20 \\
\hline TOTAL & 100 & $\mathbf{1 0 0} \%$
\end{tabular}

The above table shows the distribution of the sample members according to their knowledge of public relations strategies on administrative information systems for making basic decisions in institutions, where the results showed that the majority of the respondents consider that their knowledge of administrative information systems for a workflow is clear in making decisions in institutions especially with the development of data and information systems, Where the percentage of those strongly agreeing (20\%) of the total sample surveyed, as well as (30\%) of the sample agree on the existence of administrative information systems and that public relations have a clear vision strategy that helps in taking decisions in solving problems.

All while the ratio of non-disapprove (20\%) and disagreed strongly accounted for (20\%).

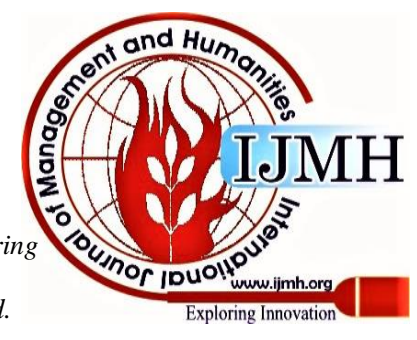


Table No. (5) Analysis of the correlation between public relations strategies between the practical managerial methods followed by the Public Relations Department in building strategic administrative communication to develop information systems in institutions.

\begin{tabular}{c|c|c}
\hline Ferries & Respondents & Percentage \\
\hline STRONGLY & 40 & 40 \\
AGREE & & \\
STRONGLY & 35 & 35 \\
NOT AGREE & 15 & 15 \\
STRONGLY & 10 & 10 \\
DISAGREE & & \\
\hline \multicolumn{2}{c}{ TOTAL } & 100
\end{tabular}

The above table shows the distribution of the sample members according to the administrative methods followed by the Public Relations Department in building strategic communication to develop the information system to work within institutions in the extent of achieving positive interaction, where the results explained that the majority of the respondents considered that the administrative information systems have an effective role in achieving interaction methods Continuity to work within the department, where the percentage of those who agreed strongly reached (40\%) of the total sample surveyed, as well as the percentage of those who Agreed with it also reached a high percentage (35\%) of the sample, while the percentage of those who did not agree (10\%) of the total sample surveyed.

Table No. (6) Analysis of the link between the public relations strategy and its strategy for organizing information and data to organize the administrative process in institutions

\begin{tabular}{c|c|c}
\hline Ferries & Respondents & Percentage \\
\hline ALWAYS & 70 & 70 \\
$\begin{array}{c}\text { SOMETIM } \\
\text { ES }\end{array}$ & 20 & 20 \\
$\begin{array}{c}\text { THERE IS } \\
\text { NO }\end{array}$ & 10 & 10 \\
TOTAL & 100 & $\mathbf{1 0 0 \%}$
\end{tabular}

The above table shows the distribution of the sample members how the public relations establish strategies for information and data to organize the process in the institutions, where the results showed that the majority of the respondents considered that always reached (70\%) of the total sample, who believe that sometimes they reached (20\%) From the sample, while the percentage who see that there is no $(10 \%)$ of the total sample surveyed.

Table No. (7) Analysis of the correlation between the contribution of the public relations strategy in administrative information systems in institutions and the identification of problems and obstacles facing them

\begin{tabular}{c|c|c}
\hline Ferries & Respondents & Percentage \\
\hline STRONGLY AGREE & 37 & 37 \\
STRONGLY & 33 & 10 \\
NEUTRAL & 10 & 33 \\
NOT AGREE & 10 & 10
\end{tabular}

The table shows the distribution of the sample members according to the contribution of the public relations strategy in the management information systems to identify the problems and obstacles facing them within the institutions, where the results showed that the majority of the sample respondents strongly agree that the public relations strategy plays an important role in the management information systems to identify problems within the institutions, where percentage of (37\%) of the total sample was reached, an centage of approval matched (33\%) of the sample, while the percentage of neutrals and disagreements reached $(10 \%)$ of the total sample surveyed.

\section{CONCLUSION}

I discussed this strategy of public relations in the use of management information systems to improve the work of institutions, where public relations in management play a leading role in developing the use of management information systems, which effectively contributed to the ocess of developing information and data technology ally and externally, and through the study, I conducted The research got some conclusions that I summarized in clarity that public relations strategies in their use of and facing the vast amount of information must be preserved in a group of systems in the form of information and data with the flow in order to facilitate internal and external audiences should obtain information in the easiest way. The study also showed that there is some difference in management information systems that differ according to the nature of the work of institutions, whether at the governmental or private el and that the function of administrative systems involves gning the required system and supervising programmers and practitioners of public relations. Moreover, each secondary system depends on other secondary systems. Also, administrative information systems and information technology systems are systems to support administrative decisions and these systems can be classified according to the inistrative tasks that relate to them. Accordingly, the study demonstrated that the majority of the respondents consider the public relations strategy in the use of administrative information systems and benefit from them in improving the work of institutions as strategies Clear to face problems and obstacles through which public relations place them in the form of values, goals and organizational policies in the form of databases of information and opinions for its internal and external audiences, as the percentage of those who agree strongly reached (37\%) of the total sample surveyed Th.

As for public relations and the effective role in achieving gic communication within institutions, the percentage of those who agree strongly reached (40\%) of the total sample surveyed.

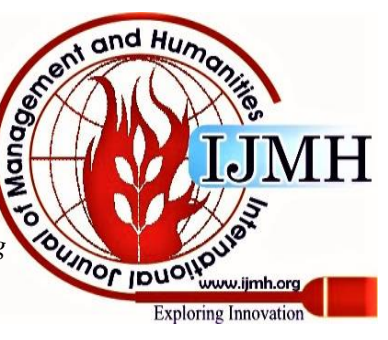


From the foregoing we conclude that the Public Relations Department must have clear strategies in its administrative work systems through classification according to the administrative tasks to which all the information that various departments need to practice the administrative process and must be accurate. To this is the necessity of increasing awareness more in the importance of management information systems in performing work in institutions and achieving creativity and excellence for the development of management information systems, and this is considered to achieve a competitive advantage in all its components. And that the Public Relations Department, as the communicating functional authority, should work to raise the level of efficiency and development of those responsible for it in a manner compatible with the work of this vital sector, through the use of modern techniques and methods in performing the work of these institutions and leaving the traditional methods. Finally, it is necessary to adopt modern experiences, specializations, and higher degrees in managing private public relations in order to advance them to more reality better than they are now.

\section{REFERENCES}

1. Abdel-Mohi Falah, Mahmoud Saleh, Jalal Al-Din Abdel-Khaleq and Mr. Ramadan, Public Relations and Information in Social Work, (Cairo: Dar Al-Maarefa Al-Jamiiah, 2014), p. 24

2. Abdullah bin Saeed, the role of administrative development management in the application of electronic management, (King Saud University: Master Thesis, College of Business Administration, 2008 AD), pp. 14-18

3. Abdul-Mu'ti Muhammad Assaf, Muhammad Falih Saleh, Foundations of Public Relations, (Amman: Hamed Library House, 2004 AD), pp. 178-184.

4. Ali Ajwa, The Scientific Bases of Public Relations, (Cairo: Books World, 2001 AD), p. 200

5. Dr. Hassan Ibrahim, The Role of Management Information Systems and Their Role in Administrative Creativity, 2011, pp. 10, 15-18

6. Hamdi Abdel-Haris Al-Bakhchungni, Public Relations from a Social Work Perspective, (Alexandria: Modern University Office, 2012 AD), p. 54

7. Hamdi Abdel-Haris Al-Bakhchungni, Public Relations from a Social Work Perspective, (Alexandria: The Modern University Office, 2012 AD), pp. 26-27

8. Hoda Sayed Latif, Public Relations, (Cairo: The Arab Publishing Company, 2017), p. 16

9. Ibrahim Sultan, Management Information System - Systems Entrance, (Cairo: University House, 2010 AD),

10. Iman Fadel Al-Samarrai and Haitham Muhammad Al-Zoubi, Management Information Systems, (Amman: Safa House for Publishing and Distribution, 2014), p. 61

11. Lebanon, Al-Shami Phone, Public Relations, Scientific Principles and Foundations, (Amman: Al-Yazouri Scientific Publishing House, 2011 AD), pp. 40-43.

12. Muhammad Muhammad al-Badi, Public Relations and the Nature of Public Opinion, (Jeddah: Dar Al-Shorouk, 2017), p. 13

13. Muhammad Qirat, Public Relations in the United Arab Emirates, (Kuwait: Al Falah Library for Publishing and Distribution, 2016), 54

14. Rasim Muhammad Al-Gammal and Khairat Moawad Ayad, Public Relations Department - Strategic Entrance, (Cairo: The Egyptian Lebanese House, 2017 AD), pp. 18-19

15. Souad Ragheb Al-Khatib, Introduction to Public Relations, (Amman: Al-Maysara Publishing and Distribution House, 2010), p. 23

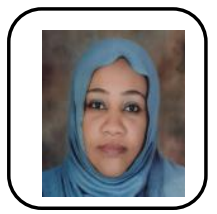

\section{AUTHORS PROFILE}

Dr. Maha Mustafa Omar Abdulaziz, Assistant Professor of Public Relations, College of Mass Communication and Public Relations, Fujairah University (UAE). She obtained a PhD in the field of public relations and advertising in the year 2012, and she has many papers published in the field of public relations, advertising and communication.
Published By: Blue Eyes Intelligence Engineering \& Sciences Publication

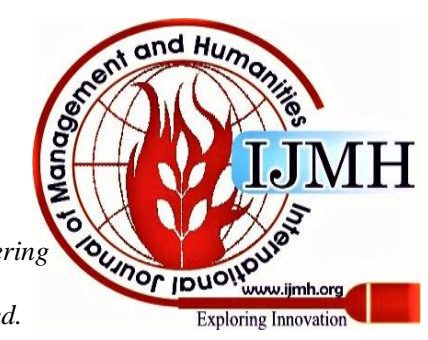

